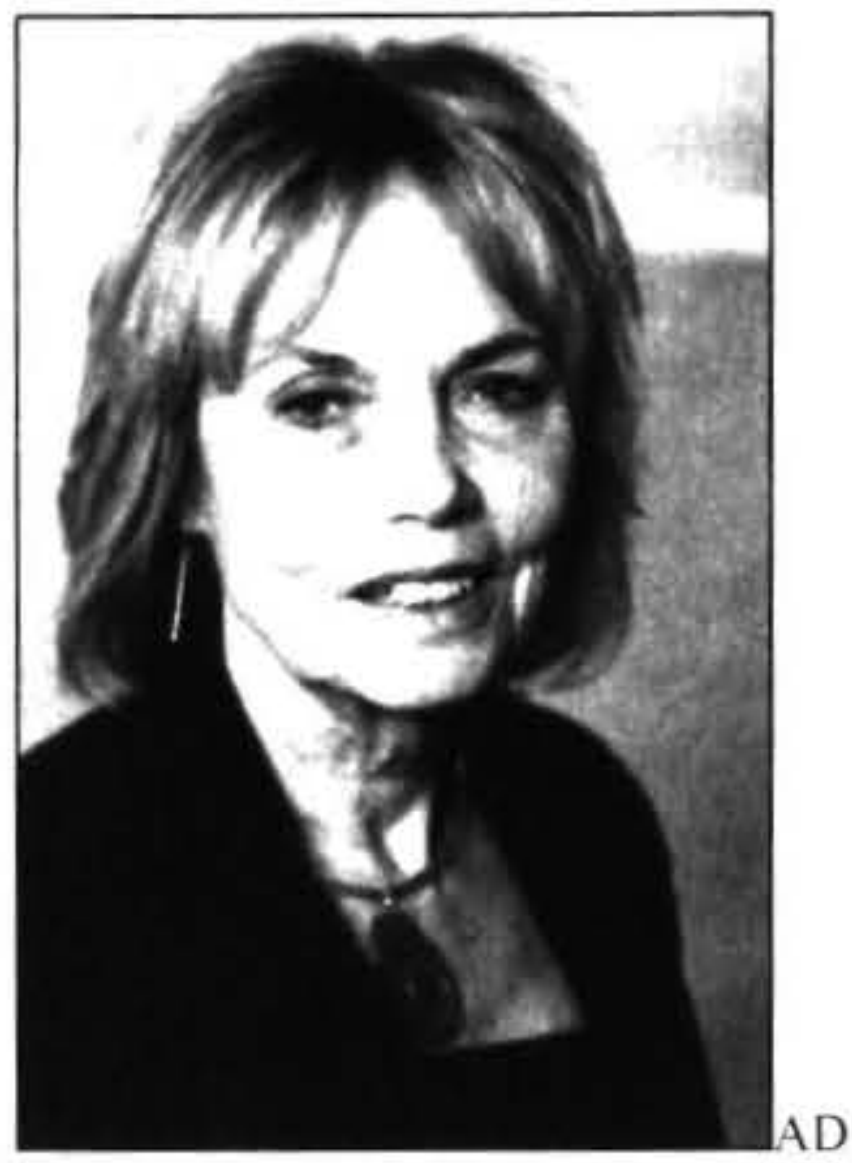

\title{
A FRAMEWORK FOR EXAMINING SUB-OPTIMAL EMPLOYMENT
}

\author{
Ann Dupuis \\ School of Social and Cultural Studies, \\ Massev University, Auckland \\ Nick Taylor
}

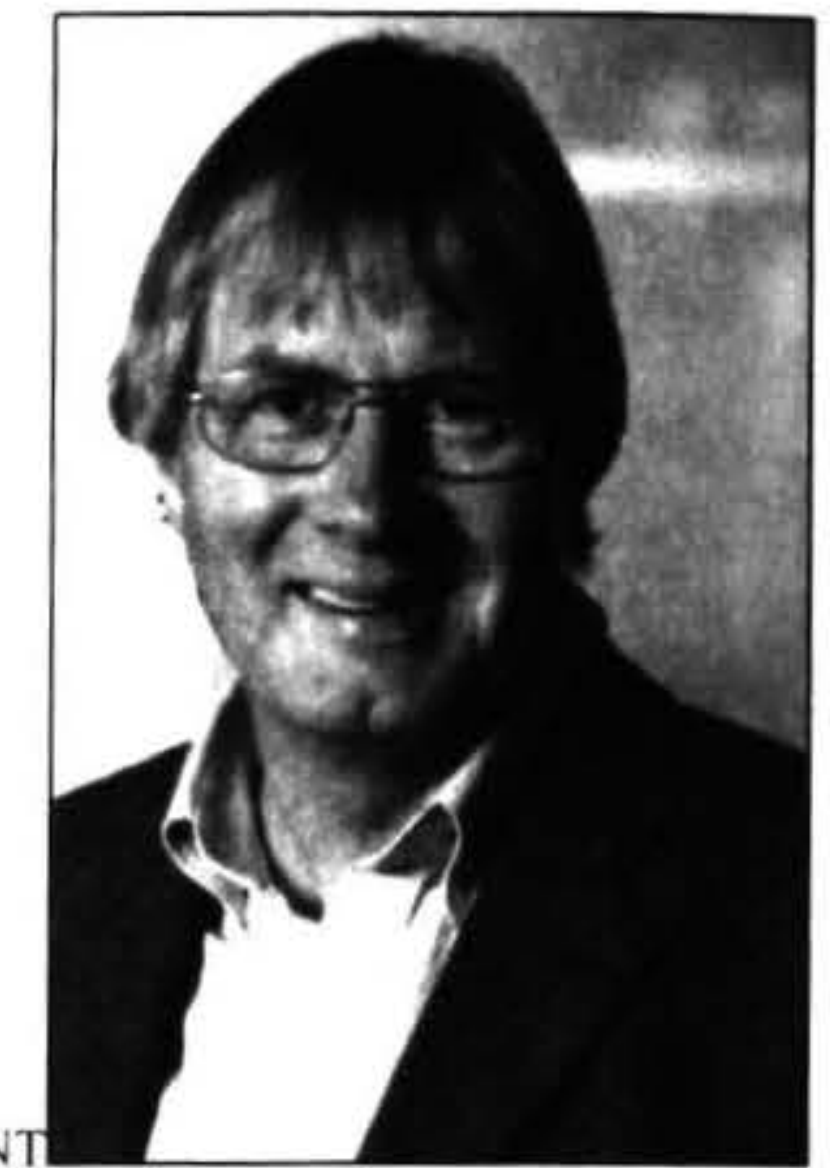

Tavlor Baines \& Associates, Christchurch

\begin{abstract}
Demographic projections for New Zealand indicate there will be major lahour shortages in the future which will not be met through either natural increase in population or immigration. It is therefore necessary that for New Zealand to retain and or improve its current economic position, the lahour force we do have is employed in ways that optimise outcomes for individuals, families/whanau and communities on the one hand, and businesses, enterprises and institutions on the other. At present, there is inadequate information ahout the labour market and employment due, in part, to the way many emplorment-related measures are defined. Additionally the importance given to two specific measures - official umemployment and lahour force participation - as indicators of a huoyant labour market, provide an incomplete picture of the complex and increasingly diverse patterns of emplorment in New Zealand. While most measures used in New Zealand mirror those used internationally and thus allow for large-scale international comparisons, much more could he done to understand shortfalls in emploiment emplosment. This paper provides a preliminary conceptualisation of sub-optimal emplorment. which emphasises the complexity of the issue under examination by suggesting the extent to which some of emplorment statuses could be considered sub-optimal.
\end{abstract}

\section{Introduction}

This paper considers the issue of sub-optimal employment in New Zealand. The adequacy of information about the labour market is directly related to the way components of the labour market are conceptualised and measured. So a preliminary conceptualisation is introduced here as a device for guiding future research.

The scene is set by considering how, in the future, New Zealand, like other OECD countries, will have increasingly fewer workers available for the work force Demographic forecasts indicate an ageing population. smaller prime working age cohorts, increasing aged dependency ratios (i.e. the number of people aged over 65 to the number aged between 20 and 64) (Ministry of Economic Development et al., 2003), and a continuing decline in fertility rates, especially with respect to Maori (Pool and Baxendine. 2006). These features, coupled with the emigration of sizeable numbers of skilled workers and the problematic issues around employment of migrants within New Zealand, indicate major concerns for future aggregate labour supply.

Over the last 15 years, labour productivity in New Zealand has grown by only 1 percent a year, which is in the bottom quartile performance across the OECD and currently, in terms of output per hour worked, is 79 percent of the OECD average (Skilling, 2006: 2). The most common response to the problem of boosting labour productivity is to demand increased worker skills, usually accomplished by investing in skills and knowledge. An additional path to increased labour productivity is to better match potential and talents with the skills needed in the workplace (DoL, 2004: 10). The extent to which this matching is inefficient represents a major component of sub-optimal employment.

It is argued in this paper that in order to make the best use of New Zealand's labour force we need to know much more about the status of workers within that labour force. Currently the most frequently cited labour market statistics are those of unemployment and labour force participation. When used in tandem, this country's low rates of 'official' unemployment and rising rates of labour force participation are widely perceived as positive features of the labour market and suggest a labour market in which people are employed at optimal levels. However, while unemployment and labour force participation rates are important labour market indicators, as they are currently defined and measured, they provide an incomplete picture of the complex, diverse and increasingly problematic patterns of employment in New Zealand. Current definitions of who is 'employed' (i.e. those who work for one or more hours per week for financial gain, or who perform unpaid work in a family business), who is 'underemployed' (i.e. those employed part-time who would like to work more hours) and who is 'unemployed' (i.e. those who are not working in a paid 
job at the survey date, but have actively looked for either full-time or part-time work in the preceding four weeks, and would have started work in the week preceding had a job been available) result in official statistics that provide narrow and sometimes misleading perspectives on the nature of contemporary employment. As such official statistics could mask major issues of sub-optimal utilisation of labour resources.

The purpose of this paper is to develop a framework which provides a means through which researchers and policy makers can work through the complexities of labour market position and identify, and thus address, areas of sub-optimality. Stimulus to undertake this task came from collaborative work between two research programmes funded by the Foundation for Research Science and Technology. These are the Labour Market Dynamics Programme of Massey University, which has examined labour markets, non-standard work and pathways to sustainable employment for younger workers, and the Taylor Baines and Associates programme of research into multiple job holding, 2003 2008. The two research teams have focussed on suboptimal employment as an important new area of labourmarket research.

This paper offers a preliminary conceptualisation of suboptimal employment. The framework demonstrates the extent of employment statuses that could be considered sub-optimal. The conceptualisation of sub-optimal employment is the first step of a proposed larger research programme which aims to calculate the extent of suboptimal employment, study its varied characteristics and offer policy-oriented research data to address the issue.

\section{The Bigger Picture}

The proposed research on sub-optimal employment recognises the erosion of standard work as the model of employment in the western world and the increase of flexible, non-standard work. Global factors propelling this shift coupled with advances in knowledge and information technology, have had profound effects elsewhere, and are impacting similarly on New Zealand's economy and labour market, especially with respect to its developing service orientation and bifurcation. Similar impacts have been noted in other OECD countries by a range of commentators. Robert Reich for example, has pointed to the quandary faced by Third Way-type governments as they 'will have to broker a new social contract between those who have been winning and those who have been losing' (Reich, 2001:6) in a 'post employment' world characterised by employment precariousness, greater levels of wage inequality, an increasing number of the employed on or near minimum wage levels, and the impact of new technologies. Similarly, Zygmunt Bauman (2004) referred to changes in the world of work that have resulted in the growth of a sizeable, disaffected marginalised minority who are no more than a worry and a nuisance, and even a substantial group of the working poor who are unable to gain sufficient financial rewards in the workplace to live in honour and dignity.
Ulrich Beck (1992; 2000) also recognised sub-optimal employment as a central component in his risk society thesis as he described global changes emanating from the demise of Fordism and the transformation brought about, especially in the service sector, by a 'risk-fraught system of flexible, pluralized, decentralized underemployment' (1992: 143). Beck argues that the growth in underemployment affects not only low-wage and lowskill jobs, but also jobs at the top of the education and skill hierarchy (such as university lecturers). The increasing casualisation of jobs across the service sector can on the one hand offer workers greater flexibility and greater control over their working lives. On the other, the increasing job insecurity that can accompany flexible work, plus the requirement for individuals to provide privately for such things as their own health care, has led Beck to see these changes as another dimension of living in a risk society and the escalation in new forms of precarious employment. It is against this body of theoretical work that our call for a greater understanding of labour market conditions and engagement is made.

\section{Conceptualising Sub-Optimal Employment}

The framework outlined in Figure 1 was developed as a heuristic device to guide a newly established research programme on sub-optimal employment. The framework is derived from three sources. First, we drew on the model of labour underutilisation developed by the Centre of Full Employment and Equity (CofFEE), University of Newcastle, Australia (CofFEE, 2002: 6). The CofFEE model divides the working age population into two groups: those in and those not in the labour force. These two groups are further subdivided and brought together into three broad categories of potential labour force participants: 'unused workers' or the official unemployed; 'underemployed workers'; and those 'unused out of the labour force'. Second, the framework was influenced by existing scholarly work on underemployment, especially Stephen Edgell's 2006 text The Sociology of Work. While focusing on time-related underemployment, consistent with the official ILO definition of underemployment, our thinking was also influenced by reference to forms of underemployment not captured in the official definition. Important too was the work of Dooley and Prause (2004) who drew on extensive data sets to demonstrate the social and health costs of various forms of underemployment and in the process work through useful definitions that were applicable to our task here. Third, the framework was further refined and extended during numerous debates and discussions among members of the team involved in the sub-optimal research programme. The framework extends considerably the Department of Labour's (2003) labour market model. However, it is still in draft form and will be refined as the research progresses. The remainder of this section of the paper explains the overall structure and the individual components of the framework.

The framework divides the working age population into those in and those not in the labour force. Those in the labour force are further divided into the official 
unemployed, the employed and the marginally employed (see Figure 1 (1)).

\section{Official Unemployed}

Unemployment has been, and still is, the predominant way of thinking about compromised labour market participation. The Statistics New Zealand definition of 'unemployed' as provided in the publication Definitions and Questionnaires relating to the 2006 Census, describes the unemployed as 'all people in the working-age population (people aged 15 years and over) who, during the week ended 5 March 2006 [the week immediately prior to Census day], were without a paid job, were available for work and: had actively sought work in the past four weeks; or had a new job to start within the next four weeks'. The definition also noted that a person whose only method of job search is looking at job advertisements in newspapers is not considered to be actively seeking work (Statistics New Zealand, 2006: 78). Examples of actively seeking work are also provided in this publication and include: directly contacting employers in various ways; contacting employment agencies, careers advisors or vocational guidance officers and Work and Income; and becoming self-employed.
It could be argued that being officially unemployed is a dimension of sub-optimal employment, in that the category comprises a group of people who are potential labour market participants, but currently unused in the labour market. As noted later in this paper, underemployment also contains dimensions of unemployment - in that an individual could be perceived as being partially employed and partially unemployed. While we have no quibble with the official definition of unemployed we argue that currently there is too much stress put on this figure, while other dimensions of suboptimal employment which are as important, if not more important, in portraying a valid picture of labour market engagement are ignored. We further argue that policy formation that does not take account of the multiple dimensions of sub-optimal employment is probably inadequate to deal with major issues in today's labour market.

\section{Emploved}

The publication Definitions and Questionnaires referred to above (Statistics New Zealand, 2006: 3) defines employed as a person 15 years or over who in the week before the Census was undertaken had:

Figure 1: Conceptualising sub-optimal employment.

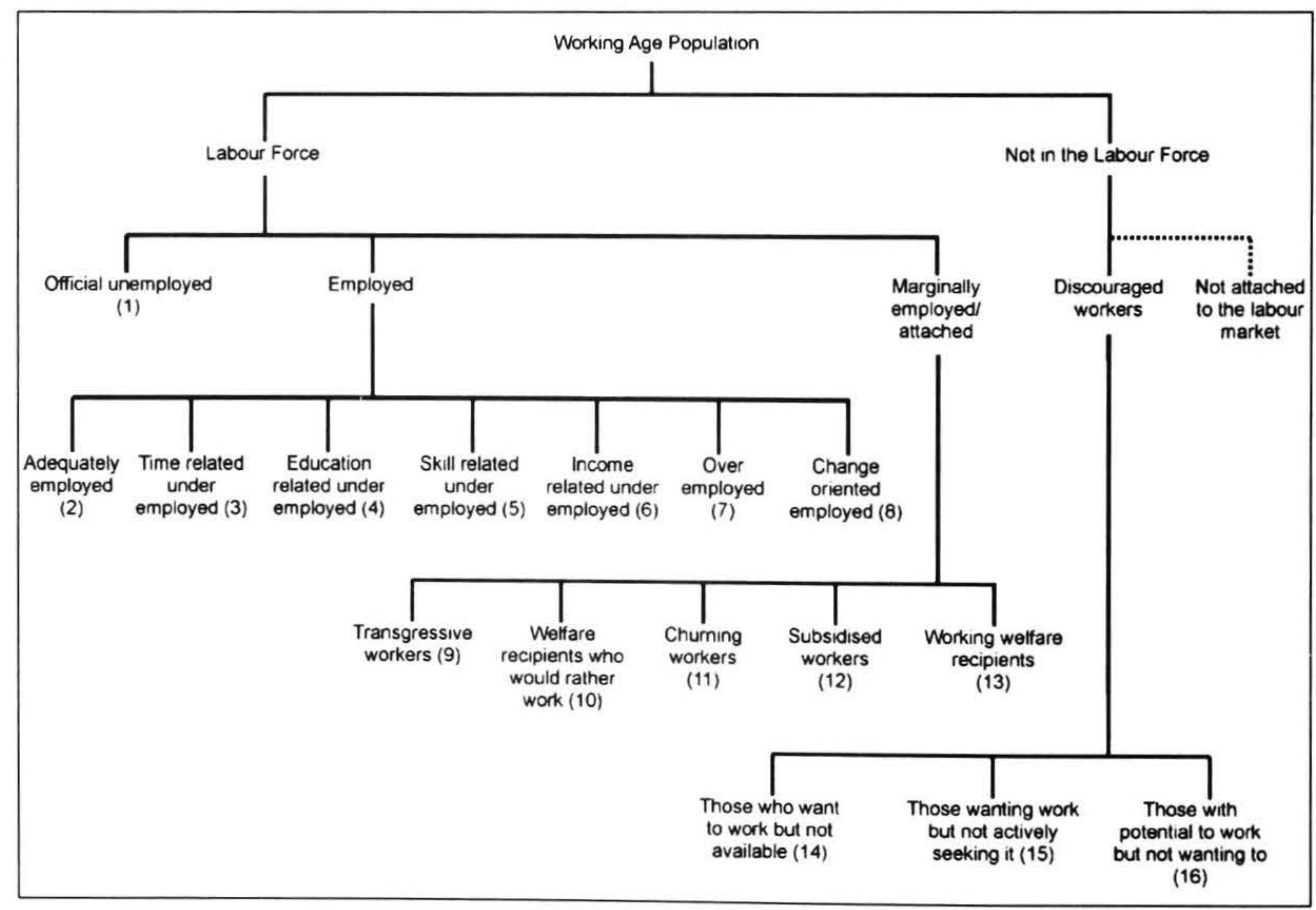


- worked for one hour or more for pay or profit in the context of an employee/employer relationship or self-employment

- worked without pay for one hour or more in work that contributed directly to the operation of a farm, business or professional practice owned or operated by a relative

- had a job but were not at work due to: their illness or injury

- personal or family responsibilities

- bad weather or mechanical breakdown

- direct involvement in an industrial dispute

- being on leave or holiday

Definitions were also provided for full-time and part-time work. The former defined as 'usually' 30 or more hours per week and the latter fewer than 30 hours per week.

The employed in our framework are divided into seven subcategories. Within the labour force there is a group of people who we assume are optimally employed. We have termed this group the 'adequately employed' (see Figure $1(2)$ ). At this time we have no basis for estimating the proportion of those in the labour force who could be categorised in this way. However, 2001 Labour Force Survey data from the United Kingdom showed that around one in five workers, or 18.9 per cent of the work force, were dissatisfied with the number of hours they worked (Simic, 2002). If other forms of inadequate employment were added to time-related inadequate employment, we could assume the proportion of the workforce inadequately employed would be considerably higher.

The remainder of the employed statuses in the framework represent forms of sub-optimal employment. Categories (3) to (5) in Figure 1 are specific forms of underemployment.

\section{Underemployed}

Defining underemployment is not an easy task. The official definition of underemployment used in New Zealand is observed in the New Zealand Household Labour Force Survey (HLFS) definition namely: 'parttime workers who would prefer to work more hours'. This definition of underemployment is consistent with the ILO definition of people of working age who are "willing to work additional hours, meaning that they wanted another job in addition to their current job(s), wanted another job with more hours instead of their current job(s) or want to increase the total number of hours worked in their current job(s)' (Simic, 2002: 512). Both definitions, however, take a narrow view of underemployment, recognising only one dimension - that of time. A broader conceptualisation of underemployment, as we have developed here, also recognises education-, skill- and income-related underemployment.

On occasion referred to as inadequate employment, irregular employment, or hidden unemployment, underemployment has been identified by the OECD
(1995) as being strongly associated with the decline in standard work and an increase in labour market flexibility. However, it is clear that underemployment, in its various guises, has been a feature of capitalism in the same way that unemployment has, and been more or less prevalent according to the general economic conditions of the times.

Underemployment, according to Quigley (2003: 61), is 'underreported and little understood'. It could also be claimed that as a phenomenon it is also under-researched. Despite the observation that 'actual levels of inadequate employment [used here as an alternative term to underemployment] have consistently exceeded actual levels of official unemployment over the last several decades' (Dooley and Prause, 2004 :23), research into these two phenomena does not reflect this fact. Searches of various databases indicate that the amount of scholarly literature and published research on unemployment far exceeds that on underemployment (ibid: 21 ).

Various attempts have been made to conceptualise underemployment. For example the Labor Utilization Framework (LUF) initially developed by Hauser (1974) has been influential in the study into underemployment and subsequent calculations of its incidence. Research from the United States reported on by Dooley and Prause (2004) that incorporated data from the three decades of the 1960s through to the 1990s, show an interesting relationship between rates of unemployment and underemployment. In years of high unemployment the ratio of underemployed to unemployed ranged from 1.5 to 2.5 , with a mean of 2 . In other words, in these "bad' years, for every unemployed person there were two people who had employment difficulties, defined as discouraged workers or time- and income-related underemployment. However, in the 'good' years, which had low unemployment rates, the ratio of underemployed to unemployed ranged from 2.7 to 4 , with a mean of $3.2-$ or for every person unemployed there were over three people who had employment difficulties. The conclusion reached was that the true challenges faced by workers, may be less visible in the "good" years than in the "bad" years, as the forms of "disguised" unemployment may be proportionately higher in the former than in the latter' (Dooley and Prause, 2004: 14). This finding is pertinent to our argument of the importance of looking beyond the binary of employed and unemployed in order to develop a greater appreciation and sensitivity for employment statuses.

Two key concerns arise from underemployment. Social costs are primarily viewed in terms of individuals whose aspirations for work are not being realised. In their influential research into the health outcomes of underemployment, Dooley and Prause (2004: 201) show that not only unemployment, but also underemployment is associated with a variety of undesirable psychosocial and health outcomes including decreased self-esteem, increased alcohol abuse and elevated depression levels. The macroeconomic costs of not fully utilising available labour resources and the inefficient use of human capital resources (education) negatively impact on productivity and economic growth (Linsley, 2005). In this regard, 
CofFEE estimated the cost of underemployment to Australia at $\$ 39$ billion per year in lost potential output; 6 percent of the GDP; or $\$ 147$ per week per Australian family.

Time-related underemployment (see Figure I (3)) is an involuntary status and arguably the most visible type of underemployment. Yates (2003: 74) describes people in this group as involuntary part-time workers ... [who] labour short hours against their wishes: they may either have had their work hours cut by their employer due to lack of business or they may want full time work but are able to find only part-time jobs'. Yates then challenges the orthodox view of underemployment and argues that 'it is reasonable to count such people as partially unemployed and add them to the officially unemployed (Yates, 2003: 74)

The importance of estimating the extent of time-related underemployment has been recognised elsewhere. For example, Simic (2002), drawing on data from the United Kingdom's 2001 Labour Force Survey, noted that 2.4 million workers ( 8.4 per cent of all employed) wanted to work longer hours. Of these, 2.1 million were available to start working longer hours within two weeks and 1.8 million were underemployed, that is, worked less than a threshold related to working time ( 46 hours for men and 41 hours for women).

Education-related underemployment (see Figure 1 (4)) refers to the situation where people are employed in a job that is below their level of education (see Kler, 2006). Two Australian studies (Kler, 2006; Linsley, 2005) provide some interesting observations on educationrelated underemployment, or in their preferred terminology, overeducation. Kler (2006: 4) argues that overeducation occurs when an individual has excess qualifications with which to do a specific job, whereas Linsley considers it is a form of labour underutilisation. Linsley argues that overeducation arises when the growth in the supply of skills that comes from increasing participation in education exeeds the growth in demand for skills. This implies that the level and composition of investment in education may be sub-optimal. She also notes overeducation can lower job satisfaction. Linsley`s paper attempts to establish the cause of overeducation. She considers a wide range of theoretical frameworks, tests four theories, and comes out in favour of one: the job competition model. This model is primarily a demand side explanation in which overeducation leads to less skilled workers being bumped down into low-skilled, low-wage positions, or crowded out of the labour market entirely. It also suggests that a proportion of the individual's investment in education has limited productive benefit, and that overall, there may be an inefficient allocation of investment in the nature and delivery of education in Australia (2005: 20).

Skill-related underemployment (see Figure I (5)) is the phenomenon whereby people are employed in a job that is below their level of skill (see Linsley, 2005). While there could be overlap between skill-related and education-related underemployment, we have chosen to keep these two categories distinct. Our rationale for doing so is that many skills are learned on the job and education alone does not necessarily develop specific workplace skills. Similarly, skills can come with experience, which again may not necessarily be solely education related.

Income-related underemployment (see Figure 1 (6)) involves work that is considered to have remuneration rates lower than market rates, including all pay that places individuals at a poverty level. This form of underemployment would result in people living in very restricted or restricted living circumstances as measured by the Ministry of Social Development's Economic Living Standard Index (Jensen et al. 2003). Sassen (2002: 73-83), in a commentary on the growth of employment-centred insecurity and poverty, notes that while insecurity and poverty have long been present in developed economies, new terms of employment may also contribute to their continuation.

Sassen's work points to a number of contradictory processes that feed into the growth and continuation of low wage jobs. For example, while much analysis proposes the need for highly educated workers, detailed empirical studies show an ongoing demand for low-wage workers, and a good supply of jobs in the old and new more service oriented economy, that require little education and pay low wages. Similarly, while some sectors of the economy like the high-tech sector are upgraded, others like the manufacturing sector have tended to include work that is downgraded. Also noted in Sassen's commentary is the increasing tendency to formalisation, especially within the downgraded sectors, as they struggle to compete. In short, Sassen (2002: 76) argues that we are seeing new employment regimes in services-dominated urban economies that create lowwage jobs and do not require particularly high levels of education".

It should be noted that these four forms of underemployment sketched above are not necessarily mutually exclusive. For example, a graduate who has had to take a part-time job in a fast-food restaurant is experiencing time, education, skill and income related underemployment, albeit temporarily.

Overemployment (see Figure 1 (7)) is also a dimension of sub-optimal employment and refers to the situation where workers are involuntarily working more hours than they want to work. Put simply, overemployment is working too many hours per week. Again overseas data gathered on this topic shows overemployment as a significant issue. For example, in the same study referred to earlier. Simic (2002), drawing on data from the 2001 Labour Foree Survey in the United Kingdom, reported that 10.5 pereent of participants (or almost 3 million workers) said that they would prefer fewer hours for less pay. It was also noted that since autumn 2000, there were more workers wanting to work fewer hours for less pay than workers wanting to work more hours. Older workers, managers, those in top paying occupations and workers with greater length of time with the same employer were most likely to want to work fewer hours for less pay.

Change oriented workers (see Figure $1(8)$ ) refer to a further dimension of sub-optimal work. This category 
comprises workers who are currently in the labour force and, while they may be satisfied with the hours worked, want to change the nature of their occupation and/or work status. An example would be contract workers who wish to change the basis of their contract (work relationships), or employed workers who are working in occupations that might use their skills and education but who want to change to a different type of occupation, even if the desired occupation requires retraining.

\section{Marginal Workers}

A further broad grouping of those within the labour force are the marginally employed, or marginally attached workers. Marginal workers are defined as those workers who are not fully integrated into the labour force but nevertheless have an attachment to it, with five categories identified (see Figure 1, (9) - (13)).

Transgressive workers (see Figure 1, (9)) is a category which includes people working in the informal economy, the black market, or moonlighting by transgressing primary employment arrangements. This category covers a range of activities from work that is legal but unreported and therefore transgressive in the sense of being outside legal regulations such as minimum wages, taxation and health and safety, to criminal activities such as drug dealing. Criminal activity is not only difficult to measure but the definition of what constitutes criminal activity changes over time, a good example of this being recent New Zealand changes to prostitution laws. There are however, approaches that have been taken to measure the extent of informal work within economies. One, the direct method, measures informal activity through surveys, and the other, the indirect method, examines discrepancies between national income and expenditure data. While both methods are described as being inherently unreliable (Thomas, 1992) it has been suggested that the ' 10 percent solution' is a reasonable guestimate of the extent of informal work in both the United States and the United Kingdom (Mattera, cited in Edgell, 2006: 143).

Welfare recipients who would rather be in paid work (i.e. those receiving a benefit other than the unemployment benefit) but are constrained from joining the work are also marginal workers. People in this category could include older workers or sole parents whose income could be threatened by engagement in the paid work force through, for example, benefit cut backs, taxation issues, or other regulatory factors (see Figure 1, (10)).

Churning workers (see Figure 1, (11)) also have a marginal attachment as they move in and out of the labour force. Churning relates to issues around job / person matches and the dissolving of these. At the broader level, analysis tends to concentrate on firm, occupation or industry churning. For workers themselves churning can be perceived in both positive and negative terms. Often workers who frequently engage and disengage with the labour force are employed in specific industries and casual and/or temporary work e.g. seasonal work
Subsidised workers (see Figure 1, (12)), such as welfare recipients who are in subsidised work schemes are marginal workers in that their attachment to the labour force occurs only as long as the scheme they are working on lasts.

Working welfare recipients whose main income is some form of benefit (see Figure 1, (13)) are also marginally attached to the labour market, thus are not counted in unemployment statistics, and work in paid employment in order to supplement their benefit.

\section{Not in the Labour Force}

Those not in the labour force have been subdivided in the framework into discouraged workers and those not attached to the labour force. The latter category is diverse and could include people who do not have a job and are on sickness benefits, or parents at home caring for their children.

Discouraged workers (see Figure 1, (14) to (16), or the 'hidden unemployed', are those workers who want work, either full-time or part-time, but are not actively seeking it because they are not available, or they think work is not available, they lack the skills to attain work, they have nowhere to look, feel too young or too old, or have other handicaps in finding a job (Dooley and Prause, 2004: 53). A second group of discouraged workers includes those people with the potential to work who do not want to work. International guidelines (ILO, 1982) suggest that the relative strength of attachment that discouraged workers feel to the labour force can be measured and that, following a change in one of the standard definitions of employed or unemployed, could be reclassified as economically active. It could also be argued that the incidence of discouraged workers should also be included in unemployment figures, thus making unemployment statistics a more reliable indicator of the true employment situation.

\section{Future Research}

The framework for understanding and analysing suboptimal employment set out in this paper was developed as a means of focusing the thinking of the authors and their research team around the nature, dimensions, and implications of sub-optimal employment. It is a first step in an ongoing, collaborative research programme. Such a conceptualisation highlights the complexity of labour market statuses. It also demonstrates the importance of not only defining labour market measures carefully, but also using them in ways that provide a valid representation of labour market connections.

It is intended for this research programme to develop robust estimates and understandings of the dimensions of sub-optimal employment. The intended examination of sub-optimal employment will challenge the orthodox conceptualisations of the boundaries and spheres that are understood as employment-related, and as a consequence highlight the issues and problems that pertain to orthodox definitional and measurement frameworks within which 
paid employment is currently understood in New Zealand.

\section{References}

Bauman, Z. (2004). Work, Consumerism and the New Poor. Maidenhead: Open University Press.

Beck, U. (1992). Risk Society: Towards a New Modernit: London; Newbury Park, Calif:: Sage Publications.

Beck, U. (2000). The Brave New World of Work. Cambridge: Malden, Mass.: Polity Press.

CofFEE (2002). Centre of Full Employment and Equity (CofFEE), University of Newcastle, Australia.

Department of Labour (2003). Work Trends: How Work is Changing in New Zealand. Wellington: Department of Labour.

Department of Labour (2004). Implementation of the Workplace Productivity Agenda: Progress Report to 30 June 2005. Wellington: Office of the Minister of Labour.

Dooley, D. and Prause, J. (2004). The Social Costs of Underemplorment: Inadequate Employment as Disguised Unemployment. Cambridge, UK New York, NY USA: Cambridge University Press.

Edgell, S. (2006). The Sociology of Work: Continuity and Change in Paid and Unpaid Work. London: Sage Publications.

Hauser, P.M. (1974). The Measurement of Labour Utilization, Malaran Economic Review; 19, 1-17.

ILO (2004). World Emplorment Report 2004-05: Emplosment. Productivity and Poverty Reduction. ILO (December, 2004), accessed February, 2006. Online:

http://www.ilo.org/public/english/employment /strat/wer2004.htm

Jensen, J., Krishnan, V., Spittal, M. and Sathiyandra, S. (2003). New Zealand living standards: Their measurement and variation. with an application to policy, Social Policy .Journal of New Zealand. 20 (June), 72-97.

Linsley, I. (2005). Causes of Overeducation in the Australian Labour Market. Paper Number 940 Melbourne: University of Melbourne.

Ministry of Economic Development, Ministry of Social Development, Department of Labour and Statistics New Zealand (2003). Population and Sustainable Development 2003. Wellington: Ministry of Economic Development, Ministry of Social Development, Department of Labour.
OECD (1995). Emplovment Outlook. OECD.

Pool, I. and Baxendine, S. (2006). Population Trends, Convictions and Imprisonment: Demographic Divergence, Dichotomy and Diversity. Discussion Paper, No. 61, Hamilton: University of Waikato.

Quigley, W. (2003). Finding Poverty as We Know It. Philadelphia: Temple University Press.

Reich, R. (2000). The Future of Success. London: William Heinemann.

Sassen, S. (2002). Deconstructing labor demand in today's advanced economies: Implications for lowwage employment. In Munger, F. (ed) Laboring Below the Line: The New Ethnogrpahy of Poverty, Low-Wage Work and Survival in the Global Economy: New York: Russell Sage Foundation.

Simic, M. (2002). Volume of underemployment and overemployment in the UK, Labour Market Trends, 110(10), 511-22.

Skilling, D. (2006). The New Zealand Economy: The Next 20 Years. Auckland: The New Zealand Institute.

Statistics New Zealand (2006). Definitions and Questionnaires: 2006 Census of Population and Dwellings. Wellington: Statistics New Zealand.

Thomas, J. (1992). Informal Economic Activity. Hemel Hempstead: Harvester Wheatsheaf.

Yates, M. (2003). Naming the System: Inequality and Work in the Glohal Economy: New York: Monthly Review Press

\section{Authors}

Ann Dupuis

Associate Professor

School of Social and Cultural Studies

Massey University

Private Bag 102-904

North Shore Mail Centre

Auckland

A.Dupuis a massey.ac.nz

Nick Talyor

Director

Taylor Baines \& Associates

P.O. Box 8620

Riccarton

Christchurch

N.Taylor $a$ tba.co.nz 